\title{
Article
}

\section{Science is not for me. Visitors' attitudes to learning in an Italian science centre}

\author{
Monia Cardella
}

Following the example of the Exploratorium in San Francisco, interactive science museums are meant to be informal and enjoyable places where visitors, regardless of their age and background, are stimulated to practice their abilities to explore the world from a scientific point of view or to reacquire it in the case of adults who are far from science for professional reasons.

Our study, which belongs to a relatively recent, but increasingly richer and complex tradition of researches on this topic, aims at contributing to answering the question whether, within the context of hands-on museums, this desired reacquisition of scientific exploration actually occurs for all visitors; more precisely, it aims at contributing to the discussion resulting from this question with reference to both possible answers and methods to find them.

The study described below was carried out for a Science Communication Master thesis in Trieste (student: Monia Cardella, supervisor: Paola Rodari) and, therefore, it is inevitably limited: in fact, in order to deal with such a complex issue and to perform more detailed investigations on the field longer time and more resources would have been necessary. However, both methods used and results obtained from it, although provisional, are significant enough to deserve our attention.

\section{Theoretical background}

The nature and modes of learning in an informal context have been among the most crucial issues of scientific museology and museology in general since the beginning of studies on visitors in the 40ies. Over the decades, the reflection on the educational impact of museums has been converging toward some unanimously accepted principles: the experience of visitors in museums can only be marginally described as a transfer of notions from exhibition curators to visitors; on the contrary, it mainly results from interactions between visitors' interests, beliefs and expectations (psychological context), those of the people involved in the production of the museal experience, those of its reference community (social context), and finally exhibits and captions (physical context) ${ }^{1,2,3}$. Therefore, there are many variables that contribute to visitors' museal experiences: demographic characteristics (sex, age, social context, background, etc.), specific reasons for visits, groups with which visits are organised, etc ${ }^{4,5}$. This is why studies on families as contexts for learning, especially through conversations between group members, are of great topical interest. ${ }^{6}$.

Moreover, the learning impact of visits on visitors has not a very precise temporal dimension: as a matter of fact, it is a cognitive experience within the temporal flow of many other life experiences that leads to confirmations, conflicts or adjustments rather than learning "here and now"7,8.

Given that science centres are meant to be places where free and personal learning is especially favoured or even encouraged in those who are no longer accustomed to it (adults), in our opinion, it was worthwhile to investigate the effects of interactions between visitors and exhibits of hands-on exhibitions: are all visitors willing to be involved by exhibits, although to a variable extent? Do they actually experience a science centre context as a place where they can practice their abilities to reason in scientific terms? What are their reactions before any given exhibit? 
We decided to study single visitors, and not groups, in order to focus on any possible learning effect resulting from given exhibits, and especially on any variation that could be observed in visitors with different characteristics before exhibits with different features.

Therefore, our objectives were: 1. testing a simple method applicable to small museums as well to assess the learning degree of visitors with reference to a given exhibition; 2. comparing the results obtained from exhibits with different communication features; 3 . showing the various visitors' attitudes to learning according to factors such as age and sex.

\section{Research methods}

The Balì Museum, inaugurated on May 15, 2004 in Saltara (PU), can be fully regarded as a science centre: it is an interactive scientific museum, based on the hands-on philosophy and intended for visitors of any age and education level, where everybody is offered the opportunity to familiarise with science in an enjoyable and autonomous way. In addition to a planetarium, an astronomic observatory for didactical purposes, several congress halls and two didactical laboratories, the museum offers an interactive permanent exhibition comprising 35 exhibits.

For our study, we deliberately selected two different exhibits: "Colour your shadow", which is a screen on which light beams from three lamps of different colours can be projected, thus producing variously coloured shadow and light areas; "Falling up", which is made of two inclined and diverging poles on which a double angular cone can be positioned. The cone, when moving freely, "raises" instead of "lowering" (this is an optical effect; in fact, the double cone lowers because its barycentre lowers). (figure 1 and figure 2)

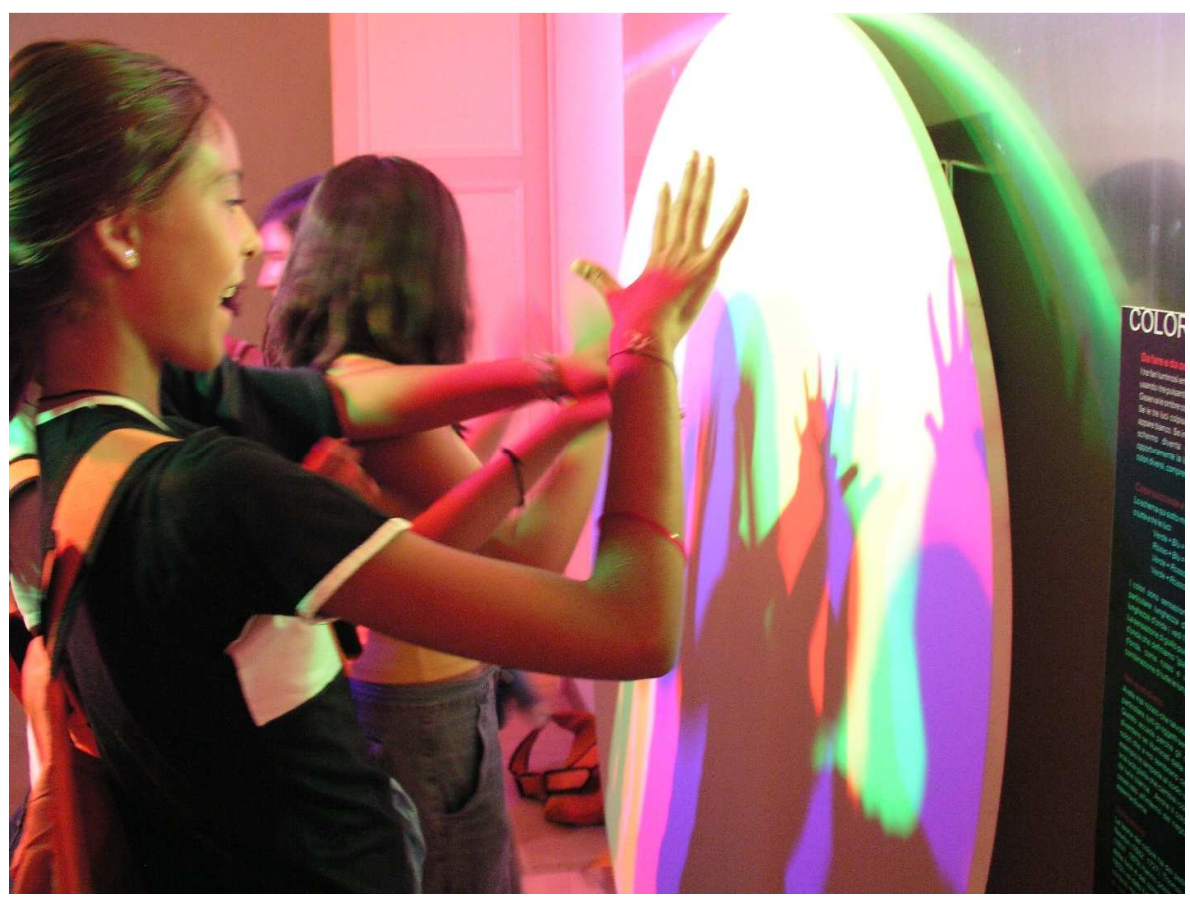

Figure 1. "Colour your shadow" exhibit at the Balì Museum, Saltara (PU) 


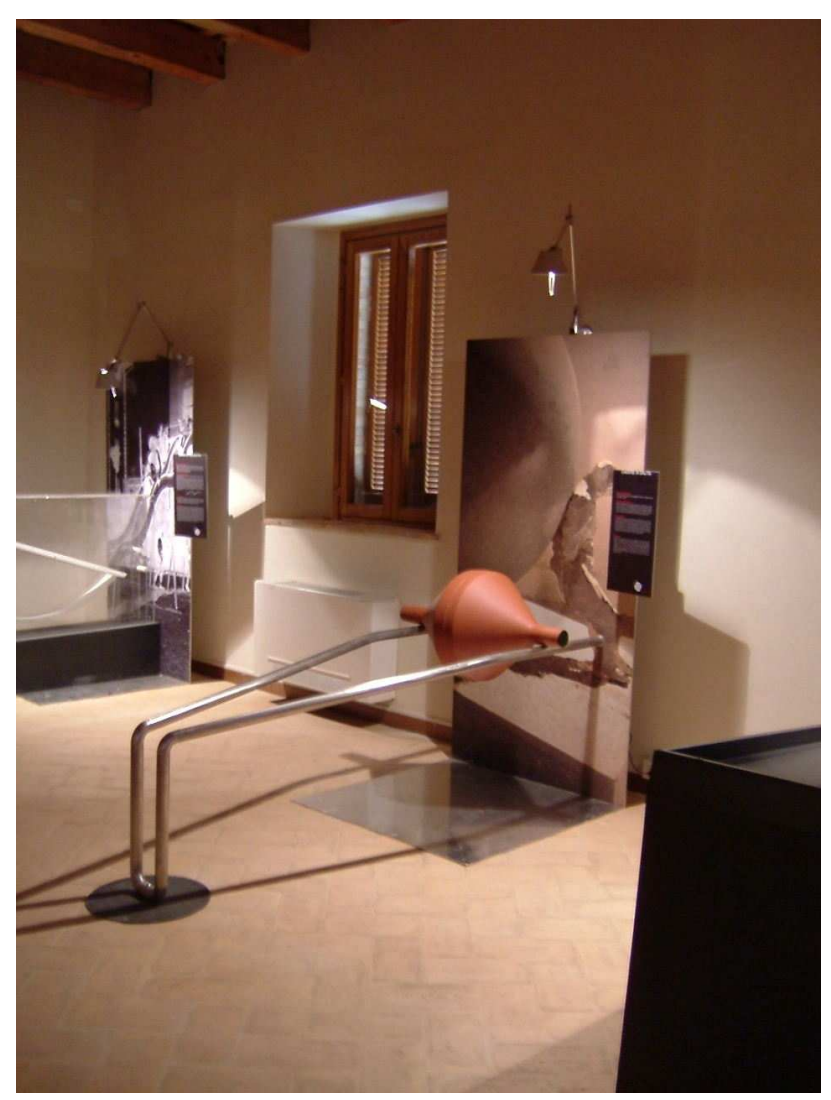

Figure 2. "Falling up" exhibit at the Balì Museum, Saltara (PU)

"Colour your shadow" is an "explorative" exhibit in that it relates to various physical phenomena connected with light properties, and it is very effective; many gestures are possible and no preset sequences are imposed to use it; visitors can "stay before the exhibit and experience it" as long as they wish and make any attempt to use it. Moreover, it is hard to say exactly what visitors should understand: they may experience changes of shadow colours when modifying the positions of lamps, or they may experience changes in shapes according to the distance and inclination of the object that is projecting the shadow, etc.

The mechanical exhibit focuses on a single phenomenon, i.e. the motion of a body that seems to move anomalously. In this case, "understanding" the exhibit has a much more restricted meaning: it means observing the apparently unnatural behaviour of the double cone and understanding that its motion is not "unnatural" at all because its behaviour can be easily explained by resorting to simple physical laws.

We analysed a small sample: 52 people, out of which 27 tried the optical exhibit and 25 tried the mechanical one. We selected visitors who were not interacting with animators. Of course, it is unquestionable that animators (as other tools such as didactical laboratories, conference cycles, animation proposals for families, etc.) are an integral part of museal communication and visitors' learning experiences. However, according to the philosophy of hands-on museums, simple interactions with exhibits should also lead to significant experiences; hence, our choice to only take into account autonomous interactions.

In order to test our method in the most general conditions, we decided not to select any specific age group; however, we preferred not to study children under the school age so as to select a sample of users that could read captions beside exhibits if they wished to.

During the first step of our study, in addition to an analysis of the exhibition and information materials made available to visitors, we interviewed four animators, who expressed their views on visitors' behaviours, especially with reference to the two exhibits under consideration.

During the second step, we unintrusively observed the behaviours of visitors dealing with the two exhibits and we took note of some personal information (their sex and age group). Moreover, we 
analysed the length of their interactions (longer than one minute or not), whether they had identified the proper operation of the exhibit and whether they had read the caption beside it.

Thereafter, when they stopped interacting with the exhibit, we interviewed them briefly. We asked them the reason for their visit, whether they could tell us the meaning of the exhibit " $x$ " with which they had played and whether they were willing to show us its operation.

Finally, their statements were classified according to a rank of levels of understanding. Although we were aware of the fact that what visitors are willing to say is not an absolute measurement of their learning (as a matter of fact, they may be unable to explain through words an interior experience, although a very important one, or they may be unwilling to talk to an interviewer), in our opinion:

1. statements of interviewed visitors always contain elements showing their levels of understanding, and the results of such an analysis are not so far from actual learning measurements, provided that the context of interviews and the fact that interviewers are recording verbal expressions of learning only, thus excluding non-verbal expressions (an approach that is accepted in all researches on learning), are duly taken into account;

2. we also took into account visitors who were not willing to talk to us, and the reasons for their unwillingness; these elements turned out to be especially significant to explain the attitudes of some visitors to museums and/or science.

We proposed five levels of understanding ranging from the lowest one (1) to the highest one (5), which correspond to five different types of visitors' statements ${ }^{9}$ :

1. refusal to talk about the experience (e.g.: "Ask him, because I have never understood such things", lady aged about 60);

2. willingness to express a judgment only in terms of appreciation/non-appreciation (e.g.: "Very nice because you can do a lot of things", girl aged about 7);

3. description of the exhibit operation (e.g.: "You must push buttons and see what happens", girl aged about 12);

4. association of the phenomenon with other events (e.g.: "It shows many colours, it is like a rainbow", boy aged about 10$)$;

5. explanation of the phenomenon (e.g.: "It is commonplace, it shows the addition of the three basic colours", man aged about 70).

Finally, the results obtained from interviews were compared with the views expressed by the four animators.

\section{Results - Quantitative aspects}

Out of the 52 visitors observed during our analysis, 27 (15 females and 12 males) interacted with the "Colour your shadow" exhibit and 25 (8 females and 17 males) interacted with the "Falling up" exhibit. All of them were randomly selected during several days of observation at the museum (November 21, December 5 and December 12, 2004).

Table 1 shows the breakdown of visitors according to age, which was assessed by the interviewer and not always confirmed by interviews.

\begin{tabular}{|c|c|c|}
\hline & $\begin{array}{c}\text { Colour your shadow } \\
\text { (no. of observed visitors) }\end{array}$ & $\begin{array}{c}\text { Falling up } \\
\text { (no. of observed visitors) }\end{array}$ \\
\hline 6 to 10 years & 6 & 3 \\
\hline 11 to 15 years & 5 & 2 \\
\hline 16 a 20 years & 1 & 2 \\
\hline 21 a 30 years & 2 & 6 \\
\hline 31 a 40 years & 5 & 4 \\
\hline 41 a 50 years & 4 & 3 \\
\hline 51 a 60 years & 3 & 2 \\
\hline 61 years and up & 1 & 3 \\
\hline
\end{tabular}

Table 1. Age groups of visitors interviewed on the two exhibits. 


\begin{tabular}{|c|c|c|}
\hline & $\begin{array}{c}\text { Colour your shadow } \\
\text { (27 visitors) }\end{array}$ & $\begin{array}{c}\text { Falling up } \\
\text { (25 visitors) }\end{array}$ \\
\hline Refusal to talk & 5 & 5 \\
\hline Judgement & 22 & 20 \\
\hline Description & 22 & 19 \\
\hline Association & 6 & 4 \\
\hline Explanation & 21 & 17 \\
\hline
\end{tabular}

Table 2. Frequency of occurrence of the five level indicators in the statements made by interviewed visitors.

This breakdown confirms the views expressed by the four animators: visitors show relatively clear preferences with reference to exhibits; children prefer the "Colour your shadow" exhibit, which on the contrary is almost neglected by adults; adults, especially males, seem to prefer the mechanical exhibit.

The different attractiveness of the two exhibits under consideration can be explained by their different natures. "Colour your shadow" is an explorative exhibit: it is not amazing that children are those most interested in it because they are more willing to be involved and inclined to grasp the playing dimension of exploration. On the other side, it is understandable that "Falling up", which is a much more monotheme and mono-use exhibit, is mainly appreciated by adults, who are more inclined to focus on a single problem and find answers to precise questions.

Out of the 52 visitors observed during this analysis, 43 visibly understood the exhibit operation and used it properly. Their levels of understanding or, more precisely, their levels of satisfaction, stimulation and inspiration are summarised in table 2 Obviously, some interviewed visitors expressed more than one statement that could be included in different categories; therefore, they appear more than once in the table.

As we can see, the majority of visitors not only expressed a value judgement, but also described the exhibit and tried to explain it. The cases of the 10 visitors who refused to answer our questions will be discussed separately.

It should be observed that associations of ideas are less frequent than explanations (10 and 38, respectively). All those who expressed associations tried to give an explanation. We were persuaded that resorting to analogies with known phenomena or objects was easier than trying to causally explain the phenomenon observed when dealing with the exhibit. On the contrary, we noted that only visitors who were able to give an explanation felt up to suggesting examples or analogies. Hence, it would seem that association results from a more complex mental process than mere explanation: first of all, I try to understand what is going on, and then I think about something similar.

Therefore, after the first interviews, we reorganised our original rank of levels of understanding as follows:

understanding 0: the person refuses to talk;

understanding 1: the person expresses a judgement;

understanding 2: the person describes the operation;

understanding 3: the person explains the phenomenon;

understanding 4: the person suggests an analogy between the exhibit and another phenomenon known to him/her.

Table 3 is a classification of the answers given by visitors according to this rank; in this table visitors

\begin{tabular}{|c|c|c|}
\hline & $\begin{array}{c}\text { Colour your shadow } \\
\text { (27 visitors) }\end{array}$ & $\begin{array}{c}\text { Falling up } \\
\text { (25 visitors) }\end{array}$ \\
\hline Understanding 0 & 5 & 5 \\
\hline Understanding 1 & 0 & 1 \\
\hline Understanding 2 & 1 & 2 \\
\hline Understanding 3 & 15 & 13 \\
\hline Understanding 4 & 6 & 4 \\
\hline
\end{tabular}

Table 3. Classification of users according to the highest level of understanding reached by them. 
are mentioned only once at the highest level reached by their statements.

The majority of visitors (21/27 and $17 / 25$, respectively) felt up to explaining what they had observed.

It is hard to classify these explanations in terms of right and wrong, and perhaps this would not be fully appropriate: as a matter of fact, according to the philosophy of hands-on museums, personal cognitive paths can vary enormously, and all of them should be respected. However, we can try and interpret the answers of interviewed visitors in terms of "right" or "wrong".

Completely right answers - answers that would be regarded as correct in a school context - were very few: 5 (out of 27 interviews) for the optical exhibit and 6 (out of 25 interviews) for the mechanical exhibit. If we accept partial or more confused explanation, we obtain the following picture that, again, shows significant differences between the two exhibits.

With reference to the optical exhibit, 21 visitors out of 27 were willing to explain the exhibit: 5 explanations were right; 4 explanations were wrong; 12 explanations were incomplete and/or confused.

With reference to the mechanical exhibit: 17 visitors out of 25 were willing to explain: 6 explanations were right; 7 explanations were wrong; 4 explanations were incomplete or confused.

Therefore, the explanations given by visitors with reference to the optical exhibit were usually incomplete in that they did not talk simultaneously about the combination of colour and the formation of shadows, but they made reference to one phenomenon or the other; however, they were rarely completely wrong. On the contrary, with reference to "Falling up", answers were usually completely right or wrong; before this apparent mechanical paradox, some visitors explicitly admitted that they did not know the reason for what was going on: out of the 11 visitors who were not able to properly interpret the phenomenon, 5 stated that they could not find any answer or, at any rate, they felt very uncertain about their assumptions.

Before "Colour your shadow", visitors did not feel uncertain, despite of the fact that the number of correct answers was comparatively slightly lower than that obtained for the mechanical paradox and incomplete answers were abundant (globally 12 out of 16 wrong answers). Probably, the optical phenomenon appears more familiar than "Falling up" and is less frightening, although it actually refers to physical laws that are often quite unknown.

The difference between the two exhibits is also confirmed by the type of value judgments expressed on them: the appreciation for aesthetics and enjoyment ("nice"; "beautiful"; "thrilling", "enjoyable") prevails when talking about "Colour your shadow", which is clearly regarded as pleasant, but familiar; with reference to "Falling up", the focus is on the strangeness and singularity of its phenomenon ("strange"; "unusual"; "unfamiliar"; "it must be a trick").

Table 4 summarises some behaviours of visitors that might be meaningful when interpreting their attitudes to the understanding of observed phenomena: length of interaction with exhibit, proper use, reading or non-reading of captions.

It clearly results that long interactions with exhibits do not automatically lead to proper explanation of them; however, all visitors who were able to explain them properly had interacted with the exhibit for a long time and, often, had read its caption. Nonetheless, it should be stressed that, with reference to length of interaction or understanding of operation, there are no significant differences between the two exhibits, but captions are used differently: the majority of visitors did not read the caption of the optical exhibit, whereas the contrary holds true for the mechanical exhibit, since the minority of them did not read it.

\begin{tabular}{|c|c|c|}
\hline & Colour your shadow & Falling up \\
\hline Length of interaction & $\begin{array}{c}\text { Long: } 15 \\
\text { Short: } 12\end{array}$ & $\begin{array}{c}\text { Long: } 16 \\
\text { Short: } 9\end{array}$ \\
\hline Understanding of operation & $\begin{array}{c}\text { Understand: } 21 \\
\text { Do not understand: } 6\end{array}$ & $\begin{array}{c}\text { Understand: } 22 \\
\text { Do not understand: } 3\end{array}$ \\
\hline Reading of captions & $\begin{array}{c}\text { Read: } 9 \\
\text { Do not read: } 18\end{array}$ & $\begin{array}{c}\text { Read: } 15 \\
\text { Do not read: } 10\end{array}$ \\
\hline
\end{tabular}

Table 4. Some behaviours of visitors before the two exhibits. 
Perhaps, the phenomenon of an object that can "falls up" is so strange that it challenges common sense and stimulates visitors to look for an explanation, also by reading its caption. On the contrary, the coloured lights of the optical exhibit convey the idea of something more "familiar" before which no need for documentation is felt. Here again, it is interesting to compare our remarks with the statements made by the four animators according to their experiences on the field.

"Before the exhibit of the three lights, you can see amazed faces, but they are less amazed than before the raising structure. After all, it is a coloured shadow; it is quite intuitive. It seems quite a natural thing. On the contrary, the raising roller is against common sense. Nothing can raise under these circumstances.." (Michelangelo)

\title{
Results - Qualitative aspects
}

So far, we have noted that a large majority of visitors use exhibits quite pleasantly, and the majority of them feel up to describing and explaining them more or less correctly. Moreover, different exhibits attract different types of visitors and raise different problems of understanding.

Now we shall move to those who, according to medical research terminology, would be called nonresponders, i.e. those who literally refused to answer our questions.

Ten visitors out of our sample of 52 people stated that they had nothing to say on the exhibit they had experienced. The non-responders for the optical exhibit were visitors who were not attracted by it and, therefore, did not even attempt to interact with it and understand its phenomenon. On the contrary, 2 visitors out of the non-responders for the mechanical exhibit interacted for a long time with it, used it properly, but did not understand it. It should be added that they were all adults.

This unexpected result confirms a situation that, unfortunately, is well known to those who operate in this field: as we grow up, we lose curiosity and intellectual openness, which are typical of children; somehow, we become reluctant to learn, unless learning is closely connected with our professional interests (our quotation).

Michelangelo, one of the four animators, said:

\begin{abstract}
"Usually, older visitors, at least those I met, just listen. They do not express their doubts. I have often experienced this situation. You can understand whether a visitor grasps a phenomenon from his/her face, regardless of his/her age. Children are more willing to make questions. They are willing to lay themselves open to uncertainty, to tell what they think about many exhibits. Before operating any exhibit, we usually ask: "In your opinion, what is going to happen?." For instance, when I set the balls free... children give tentative answers and say that they start together and arrive together... Parents, adults are less willing to give tentative answers, they are more passive. Often, when I ask: "In our opinion, what is going to happen?," many adults answer: "I do not know, it is your task to tell us". On the contrary, children are not inhibited. They are more willing... to take risks.".
\end{abstract}

Therefore, adults are less willing to talk, and some of them are more reluctant than others. A part from a couple of visitors who enjoyed the museum, but did not feel like being interviewed, all the others tended to underline that they would have been willing to talk, but they were not able to because they had not yet had the opportunity to ask or listen to an animator. Alternatively, they stated that their cultural background was not appropriate, or that they had not understood the exhibit at all, or that they were not actively visiting the museum, but they were just accompanying children, friends or relatives with special passions or backgrounds. The majority of older ladies delegated the task of understanding to others (husbands, friends, animators).

Interestingly, mothers who accompany their children seem to be the most involved visitors: they read captions loudly, they stimulate their children and follow their progress while enjoying themselves as if the fact that they must support their children's learning justifies their involvement and enjoyment.

At any rate, all statements made by visitors seem to point to the fact that science centres, just because they talk about science, are mostly suitable to children or adults with special attitudes.

The definition given by a lady is very emblematic: the museum is a container of "smart games". In order to deal with hands-on exhibits, you must be "very quick-witted", and you are quick-witted when 
you are still young (an older man said: "These things are for young people!"), or when you are smart and more interested in scientific topics than ordinary people (a grand-father proudly said: "I have always been quite a clever guy"). Therefore, according to the findings of our study, in order to appreciate science you must be a child (i.e. the desire of experimentation must prevail on the fear of external judgements) or a "special" person (a person who is convinced that he/she can speak with full knowledge of the facts); otherwise you have better keep far away from science and scientific matters (like those who admit that, decidedly, museums are not for them) to avoid cutting very poor figures when meddling with things you are not up to.

The majority of visitors stated that they enjoyed their visit and recognised the educational value of the museum; however, all things considered, they felt that they were far from science and that, somehow, they had not the means to come closer to it $^{10}$.

\section{Conclusions}

At the beginning of our study, we had three objectives: 1. testing a simple method applicable to small museums as well to assess the learning degree of visitors with reference to a given exhibition; 2 . comparing the results obtained from exhibits with different communication features; 3 . showing the various visitors' attitudes to learning according to factors such as age and sex.

Despite of the limited number of observations and the limited length of interviews, our method enabled us to identify interesting issues, which are useful for both a general discussion on learning within an informal framework and an assessment of the special context of the museum under consideration. ${ }^{11}$. Short surveys systematically carried out by animators on various exhibits would enable them to obtain a better understanding of their intuitions as natural observers of visitors, to suggest improvements, if any, to exhibits, and to interact with visitors relying on an increased awareness of their problems of understanding.

Moreover, our findings showed substantial communication differences between the two exhibits under consideration. Their attractiveness, their ability to stimulate scientific reasoning, their ability to satisfy visitors turned out to be decidedly different according to the audience. Therefore, in our opinion, wider researches aimed at classifying exhibits according to their communication features vs. the cognitive paths that they stimulate in visitors would be very interesting since they would better clarify a specific dimension of the broader issue of learning in interactive exhibitions. Presently, the researches available in this field are very few, and very few voices raise to ask them ${ }^{12}$.

With reference to visitors' attitudes, it appears that science centres have to face very tough cultural resistances. The prejudice that interactive museums are for children only and the idea of not being enough bright for science, which can only be approached by scientists or people with special characteristics (people with "a mania" for knowledge), prevent adult visitors from fully exploiting interactive exhibitions and their opportunities of enjoyment and cultural growth.

Here again, if animators and the museum staff as a whole were more aware of visitors' diversities, as well as of some stronger resistances by some categories of visitors (for instance, older ladies), then they could design special actions or merely pay special attention to stimulate those visitors during their interactions.

\section{Acknowledgements}

This research could never have been achieved without the supervision of Paola Rodari, who teaches museum studies at the SISSA Master in Science Communication. Special thanks also to the staff of the Balì Museum for their collaboration.

Translated by Quickline 


\section{Notes and references}

${ }^{1}$ The division into thee contexts (psychological, social and physical) was introduced by: J.H. Falk and L.D. Dierking, The Museum Experience, Whalesback, Washington 1992.

${ }^{2}$ G.E. Hein, Learning in the Museum, Routledge, London 1998.

3 E. Hooper-Greenhill (ed), The educational role of the Museum, Routledge, London 1994.

4 J.H. Falk, T. Moussouri and D. Coulson, The effect of Visitor's Agenda on Museum learning, Curator 41(2) (1998) 107.

5 T. Moussouri, Negotiated Agendas: Families in Science and Technology Museums, International Journal of Technology Management 25 (2003) 477. <http://dx.doi.org/10.1504/IJTM.2003.003114>

${ }^{6}$ G. Leinhardt, K. Crowley and K. Knutson, Learining Conversation in Museum. Mahwah, NJ, Lawrence Erlbaum Associates, 2000.

7 M. Barun, M. Chambers and A. Cleghorn, Families are learning in science museum, Curator 39 (2) June 1996.

${ }^{8}$ G. Leinhardt and K. Knutson, Listening in on museum conversations, AltaMira Press, Walnut Creek, CA 2004.

9 S. MacDonald, Cultural imaging among museum visitors: a case study, Museum Management and Curatorship 11 (1992) 401. <http://dx.doi.org/10.1016/0964-7775(92)90079-K>

${ }^{10}$ G. Dirbin (ed), Developing museum exhibitions for lifelong learning, GEM - Group for Education in Museums, Norwich (UK) 1996.

${ }^{11}$ For further details on this study, please see: Monia Cardella, Apprendere con gli exhibit hands-on: un case study. Science Communication Master thesis. Trieste, SISSA 2005.

${ }^{12}$ From many points of view, this classification resembles the system used in the study reported by Barun and colleagues; unfortunately, we only read it after the completion of our study: M. Barun, M. Chambers and A. Cleghorn, Families are learning in science museum, Curator 39 (2) June 1996.

\section{Author}

Monia Cardella was born in Osimo on March 16th 1975. She majored in physics and obtained a Master in Science Communication at SISSA in February 2005. She has been working for several years for the publisher Edumond Le Monnier, where she is involved in planning and drafting science text books and cd-roms for secondary schools. Email: monia.cardella@gmail.com. 